\title{
Dendritic Polyglycerol Sulfate Inhibits Microglial Activation and Reduces Hippocampal CA1 Dendritic Spine Morphology Deficits
}

\author{
Dusica Maysinger, ${ }^{\dagger \dagger}$ Dominic Gröger, ${ }^{\dagger, \S}$ Andrew Lake, ${ }^{\ddagger}$ Kai Licha, " Marie Weinhart, ${ }^{\S}$ \\ Philip K.Y. Chang, ${ }^{\ddagger}$ Rose Mulvey, ${ }^{\ddagger} \perp$ Rainer Haag, ${ }^{*}, \S$ and R. Anne McKinney, ${ }^{*}$ \\ ${ }^{\ddagger}$ Department of Pharmacology and Therapeutics, McGill University, Montreal, QC Canada \\ ${ }^{\S}$ Institute of Chemistry and Biochemistry, Freie Universität Berlin, Takustr. 3, 14195 Berlin, Germany \\ ${ }^{\perp}$ Faculty of Medicine, Imperial College, London, United Kingdom \\ "Mivenion GmbH, Robert-Koch-Platz 4, 10115 Berlin, Germany
}

\section{Supporting Information}

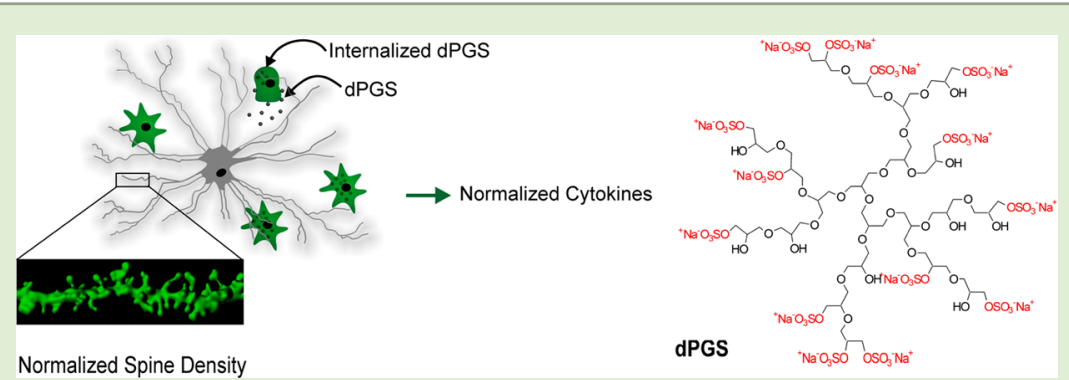

ABSTRACT: Hyperactivity of microglia and loss of functional circuitry is a common feature of many neurological disorders including those induced or exacerbated by inflammation. Herein, we investigate the response of microglia and changes in hippocampal dendritic postsynaptic spines by dendritic polyglycerol sulfate (dPGS) treatment. Mouse microglia and organotypic hippocampal slices were exposed to dPGS and an inflammogen (lipopolysaccharides). Measurements of intracellular fluorescence and confocal microscopic analyses revealed that dPGS is avidly internalized by microglia but not CA1 pyramidal neurons. Concentration and time-dependent response studies consistently showed no obvious toxicity of dPGS. The adverse effects induced by proinflammogen LPS exposure were reduced and dendritic spine morphology was normalized with the addition of dPGS. This was accompanied by a significant reduction in nitrite and proinflammatory cytokines (TNF- $\alpha$ and IL-6) from hyperactive microglia suggesting normalized circuitry function with dPGS treatment. Collectively, these results suggest that dPGS acts anti-inflammatory, inhibits inflammation-induced degenerative changes in microglia phenotype and rescues dendritic spine morphology.

\section{INTRODUCTION}

In recent years, various synthetic dendrimers and polymers as well as their conjugates with bioactives have been proposed for the manipulation and treatment of different neurological disorders, for example, a cholesterol-loaded dendrimer to modulate inflammatory signalling and cytokine release from microglia cells. ${ }^{1}$ The most widely explored dendritic architecture in this context is poly (amido amine) (PAMAM) dendrimers, which can be prepared in different generations either as neutral/cationic charged full-generation dendrimers or as anionic, carboxylic acid terminated, half-generation dendrimers. ${ }^{2}$ These soft matter nanoparticles were shown to target inflammatory cells in the brain upon subarachnoid administration, ${ }^{3}$ as exemplified by multivalent, PAMAM-N-acetyl cysteine (NAC) conjugates reported by the Kannan group. ${ }^{4}$ Besides successful targeting of neuroinflammation after intraveneous administration in pathological states, ${ }^{5-7}$ crossing the blood-brain barrier in healthy animals still remains a challenge. ${ }^{8,9}$ Nevertheless, the modification of nanoparticles, for example, with apolipoprotein $\mathrm{E}$ (ApoE), appears promising for overcoming this problem. ${ }^{10}$
Other approaches include the transport of methylprednisolone to glial cells via surface-engineered carboxymethylchitosan/ polyamidoamine (CMCht/PAMAM) dendrimers ${ }^{11}$ or the treatment of brain gliomas with a $\mathrm{pH}$-sensitive, dual targeting drug delivery system based on a complex assembly of PAMAM, transferrin, doxorubicin, and tamoxifen. ${ }^{9}$ Besides particulate systems, surface modifications and 3D matrices of synthetic dendrimers and polymers were applied to promote neuronal cell adhesion and growth. ${ }^{12,13}$ Since most neurological disorders are associated with inflammation, targeting inflammatory processes is a viable approach to identify and manipulate such diseases. Polysulfates and sulfonates are particularly attractive macromolecules for this purpose because they exhibit intrinsic antiinflammatory properties. Dendritic polyglycerol sulfate (dPGS) is a hyperbranched polyether based on a highly biocompatible polyglycerol scaffold ${ }^{14-17}$ bearing multiple peripheral sulfate groups. dPGS is a potent inhibitor of chronic inflammation

Received: July 24, 2015

Published: July 28, 2015 
through binding to L-selectin, P-selectin, ${ }^{18,19}$ and the complement factors C3 and $\mathrm{C}^{20}{ }^{20}$ It is moderately anticoagulant, has strong anti-inflammatory properties, ${ }^{21}$ and has been successfully applied in several in vivo models, for example, dermal inflammation, ${ }^{20}$ rheumatoid arthritis, ${ }^{22}$ and allergic asthma. ${ }^{23}$ Other polysulfates, for example, heparin and enoxaparin, have been proposed as candidates for the diagnosis or treatment of Alzheimer's disease, as they have already been shown to decrease amyloid precursor protein (APP) processing via $\alpha$ - and $\beta$-secretase pathways in cell cultures. $^{24}$ Microglia, parenchymal tissue macrophages, which constitute about $10 \%$ of cells in the central nervous system (CNS), ${ }^{25}$ are often named "sensors of the CNS" because they are the first to respond to an insult. ${ }^{26,27}$ Microglia modulate neural circuits by facilitating, maintaining, or inhibiting their physiological functions, thus, acting as "bad cop" or "good cop". ${ }^{27,28}$ During development, microglia eliminate inappropriate synapses, thereby promoting the proper wiring in the CNS. ${ }^{29-33}$ Disruption of normal homeostatic functions of microglia in diverse neuropsychiatric disorders leads to neuronal circuitry impairments. ${ }^{34,35}$ Functional excitatory circuitries are dependent on normal structure and function of postsynaptic dendritic spines. ${ }^{36-39}$ Spines have various shapes and sizes, and the largerhead spines, the mushroom-type, are thought to be the stronger synapse. ${ }^{40,41}$ In the present study we investigated the morphological changes of the different subtypes of spines (mushroom, thin, and stubby spines) after exposure to lipopolysaccharides (LPS) and treatment with dendritic polyglycerol sulfate (dPGS), previously shown to exert an anti-inflammatory effect in various diseases. ${ }^{20-23}$ LPS are products of Gram negative bacteria, activate microglia, and convert them from surveyors to hyperactive microglia secreting proinflammatory cytokines. ${ }^{42-47}$ Depending on their concentration, these glycolipids can either stimulate production of growth factors and protective cytokines (M2 microglia phenotype) or inflammatory cytokines (M1 microglia phenotype). ${ }^{48}$ Chronic inflammation is commonly viewed as deleterious to neurological functions. ${ }^{49,50}$ In this study, we investigated microglia and dendritic structures in hippocampal CA1 region using organotypic in vitro cell cultures in the presence and absence of dPGS. This experimental paradigm allowed for the testing of dPGS by controlling the concentration and duration of exposure of the neural cell culture to the inflammogen and anti-inflammatory dPGS. The findings suggest that dendritic polysulfates can effectively reduce cytokine production characteristic of $\mathrm{M} 1$ phenotype and normalize neural circuitries in the hippocampus. The results show that dPGS modulates the ratios of mushroom, stubby, and thin postsynaptic spines, thereby contributing to the synaptic strength, maintenance, and partial re-establishment of function in the CA1 region of the hippocampus, one of the particularly vulnerable structures in the brain commonly affected in neurological disorders. ${ }^{40,41}$

\section{MATERIALS AND METHODS}

Synthesis. Chemicals and reagents were obtained from SigmaAldrich, Acros Organics, Fischer, and Merck, and were used as received (reagent grade). Purification of the polymers was accomplished by ultrafiltration in Amicon stirred cells with regenerated cellulose membranes (MWCO $=1 \mathrm{kDa}$, Amicon/Millipore, U.S.A.). Alkynefunctionalized $\mathrm{Cy} 5$ and $\mathrm{Cy} 5 \mathrm{NHS}$-ester were commercially available from mivenion $\mathrm{GmbH}$ (Germany). Size exclusion chromatography was performed with Sephadex G-25 superfine (GE Healthcare), and RP chromatography was performed with MPLC pumps and LiChroprep RP-18 (Merck KG, Germany). Dendritic polyglycerol (dPG) was synthesized by an anionic ring-opening multibranching polymerization
(ROMBP) of glycidol using a trimethylolpropane (TMP) starter according to a reported procedure. ${ }^{51,52}$ Dendritic polyglycerol sulfate (dPGS) was prepared by sulfation of $\mathrm{dPG}$ with $\mathrm{SO}_{3}$ - pyridine complex in $\mathrm{DMF}^{20}$ and the fluorescent analog dPGS-Cy5 was synthesized by click coupling of an alkyne-functionalized indodicarbocyanine (IDCC, Cy5) derivative to the polymer, which was equipped with a $C_{11}$ linker bearing an azide. ${ }^{22}$ The control triglycerol-Cy5 was prepared by amide coupling of Cy5 NHS-ester to a monoamino glycerol G1 dendron (triglycerol). ${ }^{53,54}$

Materials. 2,5-Diphenyltetrazolium bromide (MTT), cytochalasin D, DMSO, filipin III, Griess reagent, Hoechst 33342, lipopolysaccharides from E. coli 055:B5, methyl- $\beta$-cyclodextrin, monophosphoryl lipid A from Salmonella enterica serotype minnesota Re 595, rat-tail collagen, and sucrose were purchased from Sigma-Aldrich. TNF, IL-6, and IL-10 ELISA kits were purchased from Biolegend. CLI-095 and Trypan blue was purchased from Invivogen. Dynasore was purchased from Enzo Life Sciences. Anti-S-nitrosocysteine antibody was purchased from Abcam. Antirabbit AlexaFluor 488 was purchased from Molecular Probes.

Cell Culture and Standard Treatment Protocol. N9 neonatal murine microglia were cultured in Iscove's modified Dulbecco's medium (IMDM; Gibco) supplemented with 5\% (v/v) fetal bovine serum (FBS; Gibco) and $1 \%(\mathrm{v} / \mathrm{v})$ penicillin/streptomycin (P/S; Gibco).

$\mathrm{N} 9$ microglia were seeded at $2 \times 10^{5}$ cells/well in 24-well cell culture plates (Sarstedt) and treated after $24 \mathrm{~h}$. Polymers were diluted in culture media to achieve working concentration. Cells were pretreated with polymers for $3 \mathrm{~h}$ in low-serum media (N9:1\%) before or after LPScontaining media was added for $24 \mathrm{~h}$.

Mouse Organotypic Hippocampal Slice Cultures. Organotypic hippocampal slice cultures were prepared as previously described by Gähwiler et al. ${ }^{55}$ Briefly, the slice cultures were prepared from P6-8 transgenic mice that expressed membrane-targeted eGFP under the Thy-1 promoter in a subpopulation of CA1 cells. Following decapitation, hippocampi were dissected, $400 \mu \mathrm{m}$ thick transverse slices were made, and adhered onto glass coverslips with chicken plasma clot (Cocalico Biologicals; Reamstown, PA, U.S.A.). Cultures were maintained in a roller drum incubator at $36{ }^{\circ} \mathrm{C}$ for 3 weeks prior to experimentation. Culture medium consisted of $25 \%$ heat-inactivated horse serum (Invitrogen GIBCO), 25\% Hank's balanced salt solution (Invitrogen GIBCO), and 50\% Basal medium Eagle (Invitrogen GIBCO) and was replaced weekly. Following culture preparation, synaptic connections were allowed to re-establish for 3 weeks in vitro. After the initial three-week period, dendritic spine densities reach a steady state for up to 6 weeks thereafter. Once the slice cultures are ready, they were incubated overnight in serum-free medium and then treatments were applied. Treatments consisted of dPGS/dPGS-Cy5 $(100 \mathrm{nM})$ and LPS $(100 \mathrm{ng} / \mathrm{mL})$ for $24 \mathrm{~h}$. dPGS/dPGS-Cy5 added $3 \mathrm{~h}$ prior to the addition of LPS. All animal care and treatment procedures were performed in accordance with guidelines set by the Canadian Council on Animal Care and McGill University Animal Care.

Immunofluorescence Labeling of Microglia. Following treatment, hippocampal slice cultures were fixed in $4 \%$ paraformaldehyde in $0.1 \mathrm{M}$ phosphate buffer $(\mathrm{PB})$ overnight at $4{ }^{\circ} \mathrm{C}$. Following fixation, the slices were washed in $0.1 \mathrm{M} \mathrm{PB}$, permeablized in $0.4 \%$ Triton X-100, and blocked with $1.5 \%$ heat-inactivated horse serum at $4{ }^{\circ} \mathrm{C}$ overnight. Primary antibody against ionized calcium-binding adapter molecule- 1 (Iba-1; Wako Chemicals U.S.A., Inc., Richmond, CA, U.S.A.) was added to the permeablizing buffer for 5 days at $4{ }^{\circ} \mathrm{C}$ at $1: 400$ dilution. Secondary antibody (Daylight 549; Jackson ImmunoResearch Laboratories Inc., West Grove, PA, U.S.A.) was prepared at 1:250 dilution in $0.1 \mathrm{M} \mathrm{PB}$ with $1.5 \%$ heat-inactivated horse serum and incubated overnight at $4{ }^{\circ} \mathrm{C}$. Slices were then mounted onto glass slides with DAKO Fluorescent Mounting Medium (Dako Canada, Mississauga, ON, Canada) and imaged using confocal microscopy.

Confocal Microscopy and Quantification. Fluorescently labeled microglia (Iba-1) and eGFP-expressing CA1 pyramidal neurons and astrocytes were imaged. The images were acquired using an upright Leica TCS SP2 confocal microscope (Leica Microsystems, Heidelberg, Germany) equipped with a HCX PL APO 63× NA 1.4 oil immersion objective. Image stacks were collected at $Z=0.25 \mu \mathrm{m}$ and averaged four times. Image stacks were deconvolved with Huygens Essentials software 
A

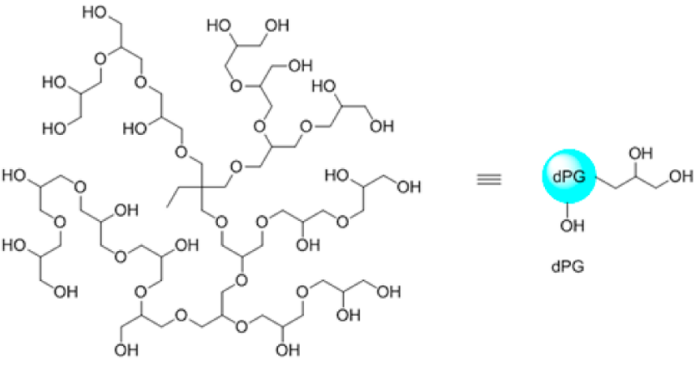

Dendritic Polyglycerol (dPG)
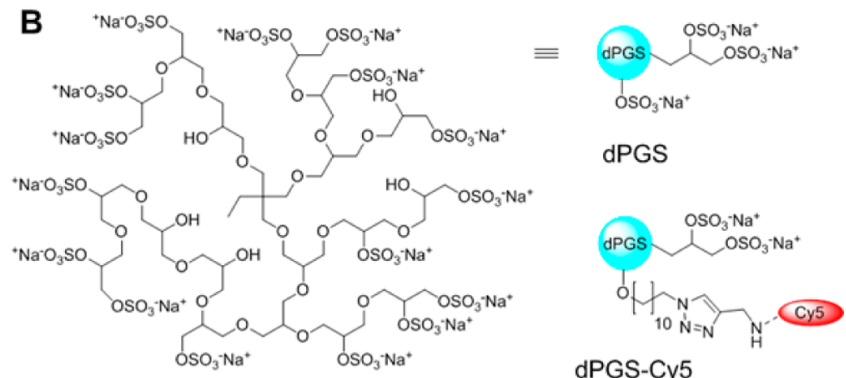

dPGS-Cy5

Dendritic Polyglycerol Sulfate (dPGS)

C
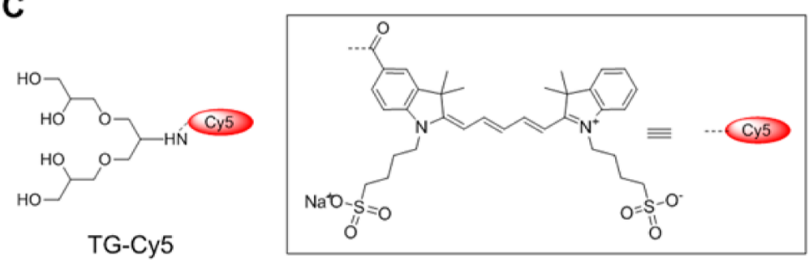

Figure 1. Chemical structures of the compounds tested in this study: (A) dendritic polyglycerol (dPG), (B) dendritic polyglycerol sulfate (dPGS) and its Cy5-labeled analog (dPGS-Cy5), and (C) triglycerolCy5 (TG-Cy5), as well as the chemical structure of indodicarbocyanine (IDCC, Cy5). The structure of the dPG scaffold is idealized.

\section{Table 1. Specification of the Tested Compounds}

$\begin{array}{lcccc}\text { compound } & \mathrm{DS}^{a}(\%) & \mathrm{NF}^{b} & M_{\mathrm{n}}{ }^{c}(\mathrm{Da}) & \text { dye loading }^{d} \\ \text { dPG } & 0 & 67 & 5000 & \\ \text { dPGS } & 95 & 64 & 11500 & \\ \text { dPGS-Cy5 } & 93 & 62 & 15100 & 0.5 \\ \text { TG-Cy5 } & 0 & 4 & 914 & 1\end{array}$

${ }^{a}$ Degree of sulfation (DS) determined by combustion analysis. ${ }^{b}$ Average number of functional groups (NF) per molecule. ${ }^{c}$ Calculated number-average molecular weight $\left(M_{\mathrm{n}}\right)$ obtained from the DS or by MALDI-ToF and GPC. ${ }^{d}$ Average dye incorporation per polymer determined by UV spectroscopy.

(Scientific Volume Imaging, Hilversum, The Netherlands) using a full maximum likelihood extrapolation algorithm. Three-dimensional rendering, volume analysis, and dendritic spine quantification was carried out using Imaris (Bitplane, Zurich, Switzerland). For volume analysis, the channel created from the fluorescently labeled cells was used to create a surface volume using the Surpass function. The generated three-dimensional objects were used to calculate the volumes of the cells and used to isolate the dPGS-Cy5 (red) fluorescence signal within the labeled green cell. Volumes for the dPGS-Cy5 contained within the cells were also generated in the same manner. Volume ratios were obtained from volume ${ }_{\mathrm{dPGS}-\mathrm{Cy} 5} /$ volume $_{\text {cell }}$ and displayed as mean volume ratio \pm SEM in arbitrary units (AU). For dendritic spine analysis, spines were classified into three main morphological subtypes,
A
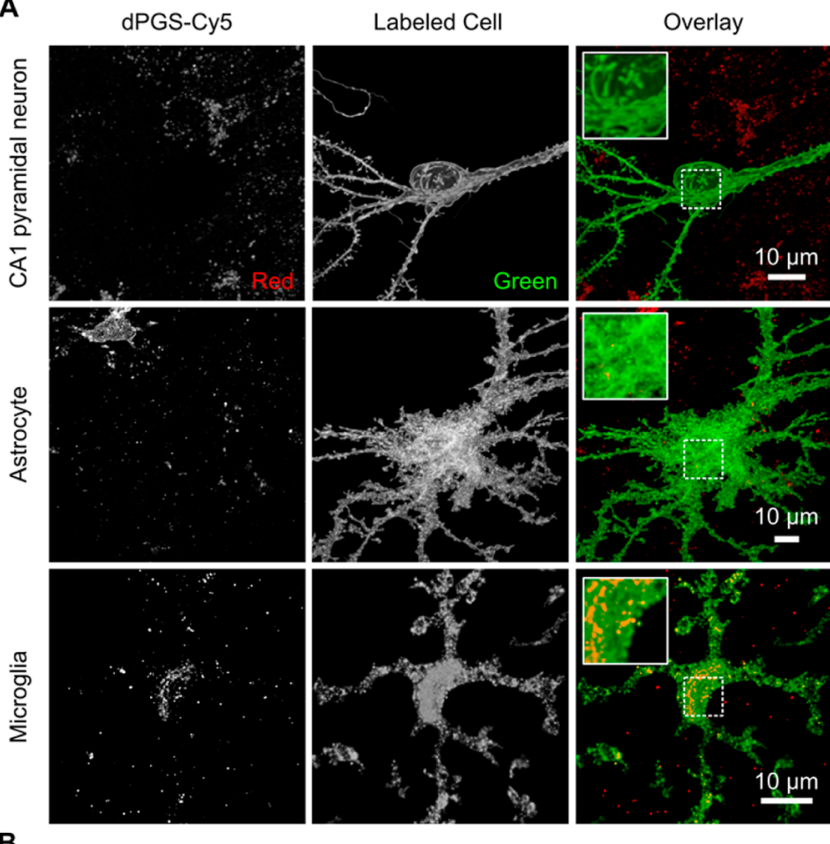

B

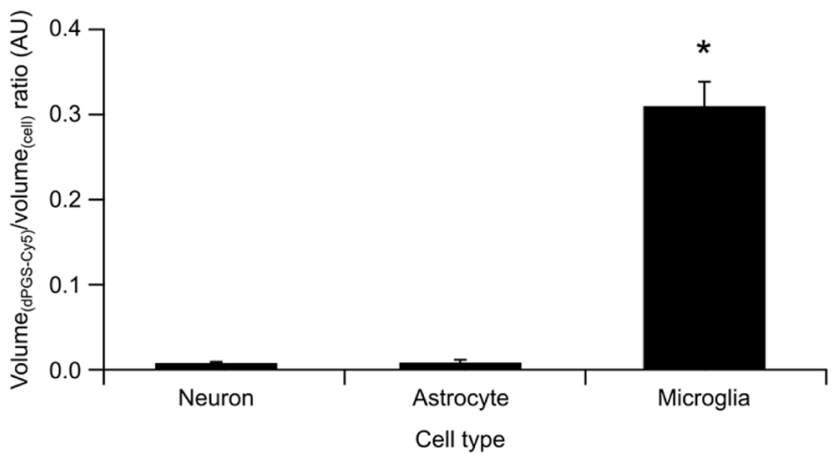

Figure 2. Exposure of organotypic cultures with fluorescently labeled dPGS. (A) CA1 pyramidal neuron, astrocyte, and microglia (green) in organotypic hippocampal slice cultures incubated with dPGS-Cy5 $(100 \mathrm{ng} / \mathrm{mL})$ for $24 \mathrm{~h}$ displays differential internalization of dPGS (red). There is a lack of red fluorescent signal inside the labeled neuron and astrocyte. However, there is a concentrated aggregation of red fluorescence signal within the immune-labeled microglia, signifying that dPGS is selectively internalized within microglia. Insets are showing areas surrounded by dotted line that are magnified to indicate the presence or absence dPGS-Cy5 colocalization within the different cells. (B) Quantification of fluorescence signal overlap between the green and the red channels. Volumes of the red and the green fluorescence channels are calculated from the three-dimensional reconstruction of the confocal image stacks. Ratio between the two channels are calculated as volume dPGS $_{\text {volume }}$ cell and is expressed as mean decimal values \pm SEM AU. There is very little dPGS fluorescence signal within both the neurons $(0.0071 \pm 0.0011 \mathrm{AU} ; n=18$ cells from 15 cultures $)$ and the astrocytes $(0.0078 \pm 0.0029 \mathrm{AU} ; n=10$ cells from 10 cultures $)$ compared to microglia ( $0.31 \pm 0.028 \mathrm{AU} ; n=27$ cells from 16 cultures); $* p<0.05$.

stubby, mushroom, and thin-type spines using previously established methods based on the measurements of spine head and neck diameters (McKinney 2010).

Mitochondrial Metabolic Activity. Mitochondrial metabolic activity was assessed in N9 cells using the MTT assay. Following treatment, medium was removed and replaced with serum-free medium containing MTT (3-(4,5-dimethylthiazol-2-yl)-2,5-diphenyltetrazolium bromide; $5 \mathrm{mg} / \mathrm{mL}$ ). Cells were incubated at $37^{\circ} \mathrm{C}$ for $45 \mathrm{~min}$ after which medium was removed. DMSO was then added to lyse the cells 
A

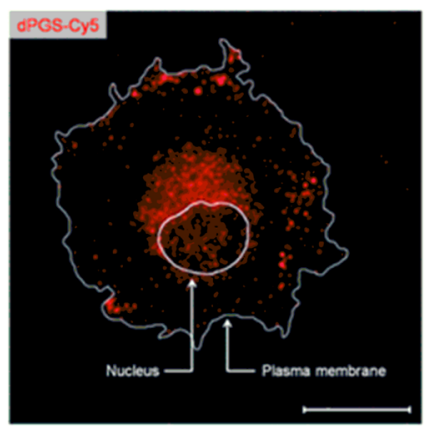

C

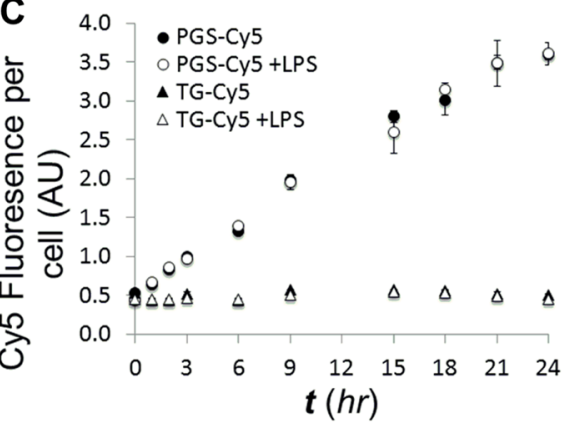

B

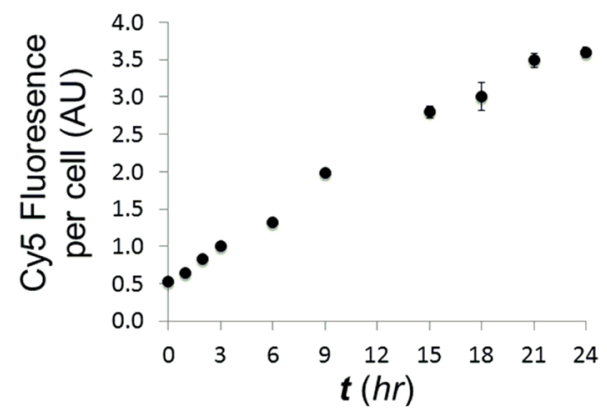

D

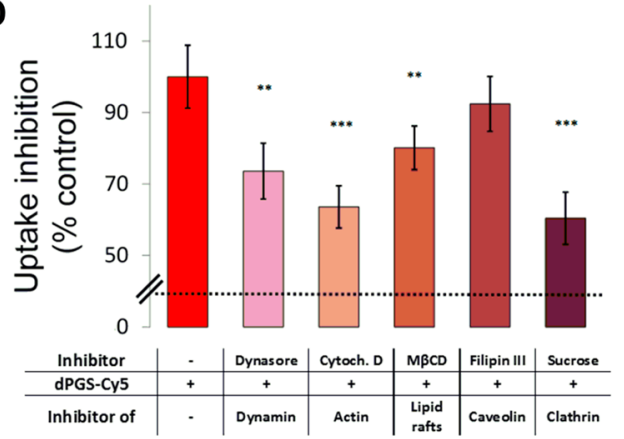

Figure 3. Uptake of dPGS into N9 microglia. (A) Confocal image of N9 microglia treated with dPGS-Cy5 (100 nM) for 1 h shows dPGS-Cy5 association with the plasma membrane and inside the cell but mainly outside the nucleus. Scale bar: $20 \mu \mathrm{m}$. (B) Time course of dPGS-Cy5 (100 nM) internalization by $\mathrm{N} 9$ microglia. (C) Internalization of dPGS-Cy5 or TG-Cy5 $(100 \mathrm{nM})$ by N9 microglia in the presence and absence of LPS $(100 \mathrm{ng} / \mathrm{mL}, 3 \mathrm{~h})$. Cells were then fixed, and Cy5 fluorescence was measured by the Operetta high-throughput cell analysis system. Mean values and standard error of the means for quadruplicate measurements from at least two independent experiments $(n \geq 8)$ are shown. (D) Polymer uptake inhibition in N9 microglia. Cells were treated in IMDM supplemented with $1 \%$ FBS with $100 \mathrm{nM}$ dPGS-Cy5 for $1 \mathrm{~h}$ following pretreatment with various pharmacological inhibitors $80 \mu \mathrm{M}$ dynasore for $30 \mathrm{~min} ; 5 \mu \mathrm{M}$ cytochalasin $\mathrm{D}$ (cytoch. D) for $30 \mathrm{~min} ; 5 \mathrm{mM}$ methyl- $\beta$-cyclodextrin $(\mathrm{M} \beta \mathrm{CD}$ ) for $30 \mathrm{~min}$; $1 \mu \mathrm{g} / \mathrm{mL}$ filipin III for $30 \mathrm{~min}$; $0.45 \mathrm{M}$ sucrose for $1 \mathrm{~h}$. Cells were then fixed, and Cy5 fluorescence was measured by the Operetta high-throughput cell analysis system. A decrease of uptake in the presence of the pharmacological inhibitor is expressed as \% inhibition relative to the values in the absence of the inhibitor (considered a positive control, $100 \%$ uptake). All values were normalized to the cell numbers per well and expressed as mean values and standard error of the means for quadruplicate measurements from at least two independent experiments $(n \geq 8)$ are shown.

and dissolve the formazan produced. Triplicates from each well were collected into a 96-well plate (Sarstedt), and the absorbance at $595 \mathrm{~nm}$ of each well was measured using a Benchmark microplate reader (Bio-Rad, Mississauga, ON, Canada).

NO Release. Nitric oxide (NO) release from N9 cells, and from hippocampal organotypic cultures was measured using the Griess Reagent ( $1 \%$ sulphanilamide, $0.1 \% N$-(1-naphthyl)ethylenediamine dihydrochloride, $5 \%$ phosphoric acid). Following treatment, $50 \mu \mathrm{L}$ of the supernatant from each well was taken in triplicate into a clearbottom 96-well plate (Corning), mixed with $50 \mu \mathrm{L}$ of Griess reagent, and incubated at room temperature for $15 \mathrm{~min}$. Standard curves were prepared in triplicate with each experiment, and NO concentration was calculated by use of standard curve as reference. Absorbance at $540 \mathrm{~nm}$ for each sample was measured using the microplate reader.

ELISA. TNF- $\alpha$ and IL- 6 release from N9 cells and hippocampal organotypic cultures was measured using ELISA (Biolegend). Following treatment, samples were appropriately diluted and assessed according to the manufacturer's protocol. Standard curves were prepared in duplicate with each experiment, and cytokine concentration was calculated by use of standard curve as reference.

Cell Counting and Trypan Blue Staining. Cell number and cell death was quantified in microglial cells by trypan blue staining and hemocytometry. Following treatment, cells were harvested with their supernatant) and centrifuged at $4{ }^{\circ} \mathrm{C}$ for $5 \mathrm{~min}$ at $3000 \mathrm{rpm}$ and resuspended in 4:1 PBS/trypan blue. The cell suspension was diluted and $10 \mu \mathrm{L}$ was loaded into a hemocytometer (Hausser) and the cells were counted. Cell number was also assessed by labeling nuclei (Hoechst 33342). In short, microglia were fixed with $4 \%$ paraformaldehyde for $15 \mathrm{~min}$ and labeled with Hoechst $33342(10 \mu \mathrm{M})$ for $15 \mathrm{~min}$. The cells were washed and kept in phosphate buffered saline (PBS) for imaging. Cell imaging was conducted using an automated microscopy platform (Operetta High Content Imaging System; PerkinElmer). Image analysis and cell counting was performed using the Columbus Image Data Storage and Analysis platform (PerkinElmer).

Uptake Analysis. N9 microglia were seeded at $1 \times 10^{4}$ cells/well in a black-well clear-bottom 96-well plate (Corning). Following treatment (30 $\mathrm{min}$ to $24 \mathrm{~h}$ ), cells were fixed in $4 \%$ paraformaldehyde for $15 \mathrm{~min}$ at room temperature and stained with Hoechst $33342(10 \mu \mathrm{M})$. dPGS-Cy5 fluorescence was measured using the Operetta high-content screening system (PerkinElmer) and analyzed with corresponding Harmony image analysis software (PerkinElmer). For each well, 11 images were acquired with a $20 \times$ objective. Individual nuclei were identified within each image based on the Hoechst channel, and per-cell Cy5 fluorescence was based on the Cy5 channel.

Statistical Analysis. All data are expressed as mean \pm SEM and analyzed by ANOVA, as indicated. When significance was obtained by ANOVA, Dunnett's posthoc test was used to compare values between treatments; $* p<0.05, * * p<0.01$.

\section{RESULTS AND DISCUSSION}

1. Synthesis. The compounds tested in this study were prepared by applying previously reported synthetic procedures. In brief, hydroxyl-terminated dendritic polyglycerol (dPG, average number molecular weight $M_{\mathrm{n}}=5.0 \mathrm{kDa}$, Figure 1A) was prepared by an anionic ring-opening multibranching polymerization (ROMBP) of glycidol on a partially deprotonated trimethylolpropane (TMP) starter by applying slow monomer addition (SMA). ${ }^{51,52}$ Nonlabeled dendritic polyglycerol sulfate (dPGS, $M_{\mathrm{n}}=11.5 \mathrm{kDa}$, Figure 1B) was prepared by sulfation 

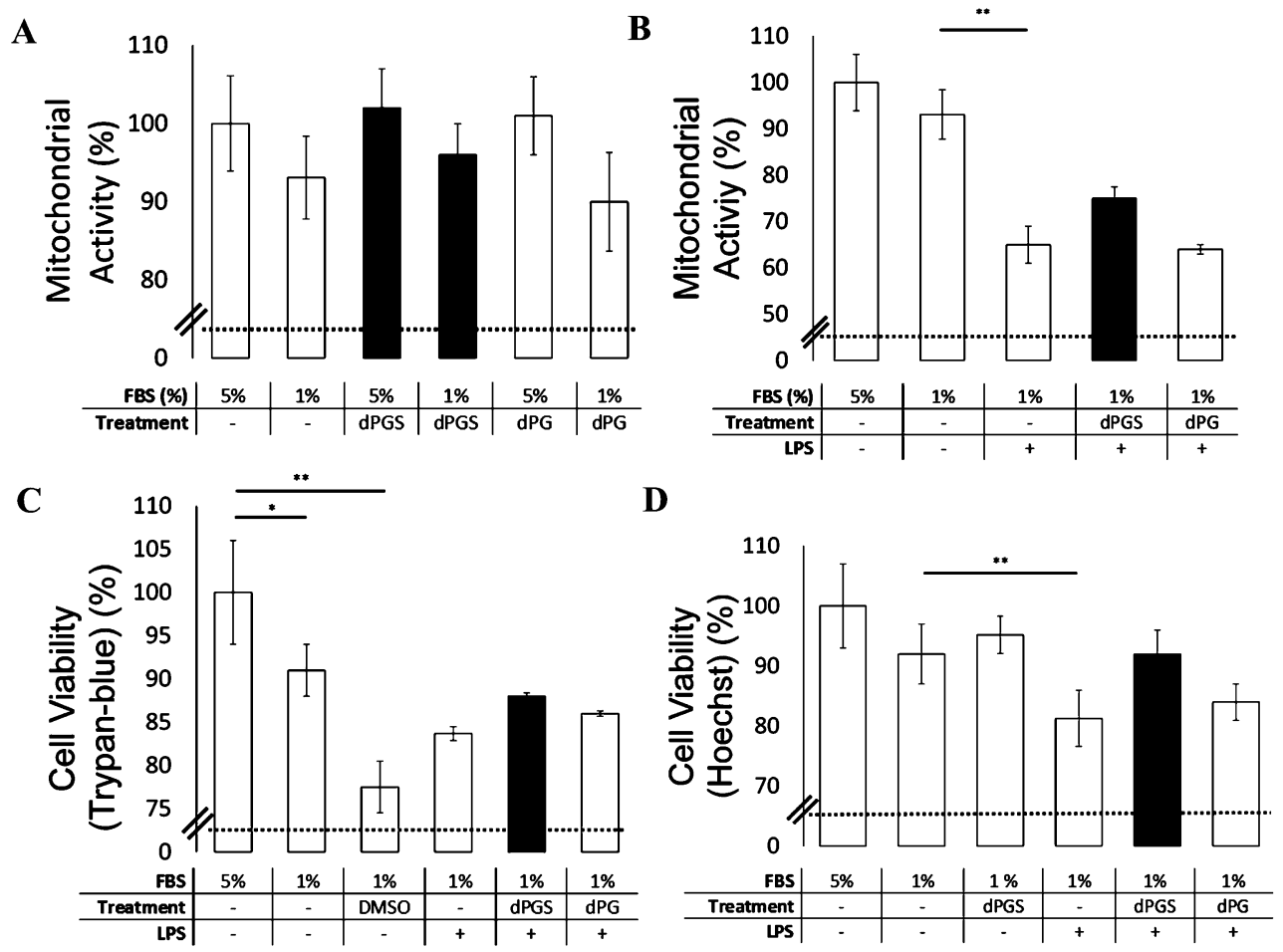

Figure 4. Cell viability assays: dPGS toxicity in N9 microglia in IMDM supplemented with 1\% FBS. Microglia are maintained in the presence of 5\% FBS (considered as control, 100\% viability). Note: All experiments were performed with 1\% FBS and all treatments were compared with viability and metabolic activity in the absence of dPGS or dPG but with $1 \%$ FBS. Cells were treated (A) with dPG and dPGS (100 nM) for $24 \mathrm{~h}$ and (B) with dPG and dPGS $(100 \mathrm{nM})$ for $3 \mathrm{~h}$ followed by LPS $(100 \mathrm{ng} / \mathrm{mL})$ for additional $24 \mathrm{~h}$. Mitochondrial metabolic activity was measured by the MTT assay; values are expressed as a percentage reduction in mitochondrial metabolic activity relative to untreated control cells. (C) The cell viability was determined by hemocytometry in N9 microglia treated with dPG and dPGS $(100 \mathrm{nM})$ for $3 \mathrm{~h}$ followed by LPS $(100 \mathrm{ng} / \mathrm{mL})$ for an additional $24 \mathrm{~h}$. Cell viability percentage was calculated by dividing the live cell number (trypan blue-negative) by the total cell number. (D) Viability of microglia measured by highthroughput analysis of labeled nuclei with Hoechst 33342. Mean values and standard error of the means for triplicate measurements from at least two independent experiments $(n \geq 6)$ are shown; $100 \%$ cell viability corresponds to $5 \%$ FBS. Significant differences: $* p<0.05, * * p<0.01, * * * p<0.001$.

with $\mathrm{SO}_{3}$ pyridine complex in $\mathrm{DMF}^{20}$ and the Cy5-labeled analogue (dPGS-Cy5, $15.1 \mathrm{kDa}$, Figure 1B) was synthesized by introducing an azide bearing $\mathrm{C}_{11}$ linker prior to the sulfation process and click coupling of an alkyne-functionalized Cy5 derivative in the last step. ${ }^{22}$ The low molecular weight control triglycerol-Cy5 (TG-Cy5, Figure 1C) was prepared by amide coupling of an NHS activated Cy5 (Cy5 NHS-ester) ${ }^{53}$ to a glycerol G1 dendron (triglycerol) functionalized with an amine group at the focal point. ${ }^{54}$ Purification of the compounds was accomplished by ultrafiltration, size exclusion chromatography, and reverse-phase column chromatography.

The prepared polymers dPG and dPGS are highly watersoluble probes and have a hydrodynamic diameter of approximately 5-6 $\mathrm{nm}$ in phosphate buffered saline. ${ }^{19}$ Average number molecular weights and the number of peripheral functional groups, as well as the average dye incorporation per polymer is given in Table 1. For cellular uptake studies and visualization, the Cy5-labeled variant of dPGS (dPGS-Cy5) was used, whereas for the quantification of cytokine release and NO production, as well as the impact on dendritic spines, unlabeled dPGS was used.

2. Cellular Uptake and Cell Viability. First, we investigated if the dPGS was internalized into pyramidal neurons and if it was toxic to organotypic hippocampal brain slice cultures. Cellular uptake was investigated using confocal microscopy on organotypic hippocampal slice cultures which were incubated with dPGS-Cy5 for $24 \mathrm{~h}$ at a concentration of $100 \mathrm{nM}$ (Figure 2). Interestingly, when different cell types (CA1 pyramidal neurons, astrocytes, and microglia) were examined, neither dPGS-Cy5 alone nor in the presence of LPS (Supporting Information, Figure SI1) did appear to enter CA1 pyramidal neurons. Rather, there was a selective aggregation of $\mathrm{dPGS}-\mathrm{Cy} 5$ positive signal within microglia. This suggests that dPGS could be taken up in a cell-specific manner.

When investigating the toxicity of dPGS toward CA1 pyramidal neurons after $24 \mathrm{~h}$ by measuring mitochondrial metabolic activity (MTT) or cell death (propidium iodide labeling), no detrimental effects on the health of the organotypic culture were observed. Next we investigated if dPGS labeled with Cy5 (dPGSCy5) was taken up into microglia N9 cells (Figure 3). These cells were selected because it is known that they have many properties similar to primary microglia cultures, which was confirmed in a previous publication. ${ }^{47,56}$ Seeing that dPGS was nontoxic in microglia at a concentration of $100 \mathrm{nM}$ (MTT assay, trypan blue exclusion assay and Hoechst 33342 labeling of cell nuclei, see below), we investigated if this lack of toxicity could be explained by their inability to enter the cells and only temporarily bind to plasma membrane putative selectin receptors. ${ }^{20,53}$ For this we used dPGS-Cy5 and the control triglycerol-Cy5 (TG-Cy5) and untreated cells (controls for autofluorescence). Imaging of live cells by fluorescence microscopy (Figure 3A) and $z$-stack analyses together with the measurements of relative fluorescence intensities by high-throughput imaging (Operetta) and spectrofluorometry provided a clearly time-dependent course of internalization of the fluorescent compounds (Figure 3B and 3C). The extent of internalization into microglia was significantly 
A
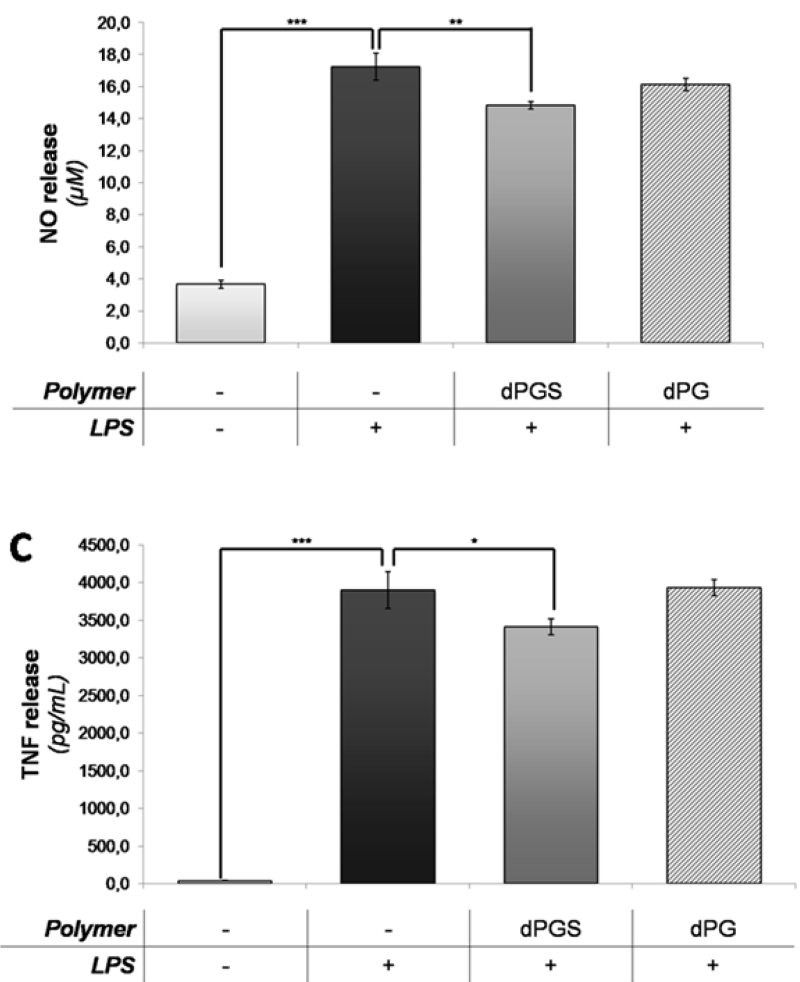

B
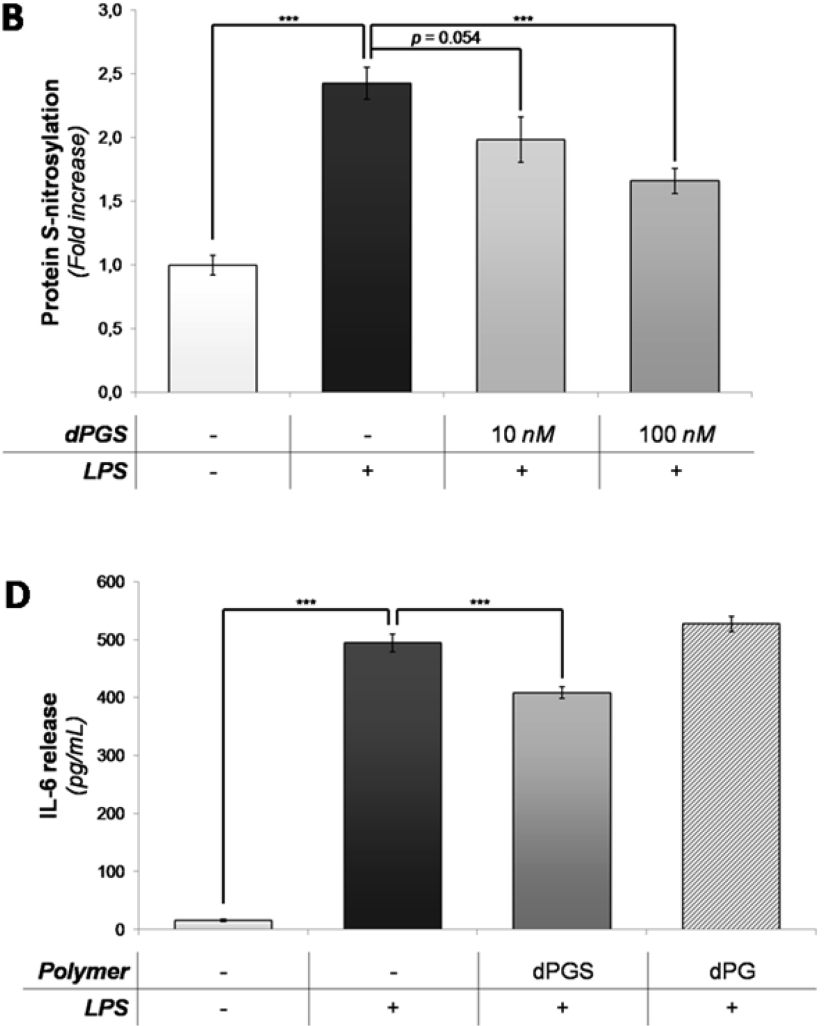

Figure 5. Inflammatory biomarker production in N9 microglia: Nitric oxide release, protein S-nitrosylation, and cytokine release. Cells were treated with dPG and dPGS (100 nM) for $3 \mathrm{~h}$, followed by LPS $(100 \mathrm{ng} / \mathrm{mL})$, for an additional $24 \mathrm{~h}$ in IMDM supplemented with $1 \%$ FBS. (A) NO release was measured by the Griess assay, (B) $S$-nitrosylated proteins in individual cells were quantified by immunocytochemistry; values are expressed as a fold increase in fluorescence relative to untreated control cells. (C) TNF- $\alpha$ and (D) IL- 6 release were measured by ELISA. Mean values and standard error of the means for triplicate measurements from at least two independent experiments $(n \geq 6)$ are shown. Significant differences: $* p<0.05$, $* * p<0.01, * * * p<0.001$.

higher for dPGS-Cy5 than for the control TG-Cy5 and the extent of their internalization (in the presence of $100 \mu \mathrm{g} / \mathrm{mL}$ LPS) at this time point $(24 \mathrm{~h})$ was not significantly altered by LPS (Figure 3C). The internalized dPGS-Cy5 could be clearly detected inside the microglia as well as associated with plasma membrane after $1 \mathrm{~h}$ of incubation and significantly more after longer times (15-24 h, Figure 3A,B). We next investigated the mode of dPGS entry into microglia. For this, we performed several pharmacological manipulations to reveal which of the internalization routes are the most likely ones. Unfortunately, the selectin-specific antibodies are not commercially available. Therefore, we used commonly studied uptake inhibitors, that is, dynosore (to inhibit dynamin-mediated internalization), cytochalasin D (Cytoch. D, to derange actin cytoskeletal structures essential for several routes of internalization, including macropinocytosis), methyl- $\beta$-cyclodextrin ( $\mathrm{M} \beta \mathrm{CD}$, to inhibit internalization via lipid rafts by depleting cholesterol from the plasma membrane), filipin III (to inhibit caveolin-mediated internalization), and sucrose (to inhibit clathrin-mediated endocytosis; Figure 3D). We found that dPGS-Cy5 utilizes several routes of entry, except caveolin. The most pronounced inhibition was measured when microglia were exposed to cytochalasin D. Since cytochalasin D disrupts actin cytoskeleton and interferes with several modes of internalization, macropinocytosis is likely one of them; it is a common mode of internalization by macrophages and it is associated with engulfment of extracellular fluid and pathogens by actin-rich plasma membrane. ${ }^{57,58}$ It was found that other dendrimers are also internalized via this route of cell entry (Anticancer drug nanomicelles formed by self-assembling amphiphilic dendrimer to combat cancer drug resistance. ${ }^{59}$ In addition, dPGS-Cy5 did not aggregate to be taken up by phagocytosis. Internalization by phagocytosis depends on LPS but micropinocytosis does not. These findings are intriguing and merit further examinations by changing the expression, for example, knock-down and overexpression, of key internalization proteins in microglia. An understanding of the roles of individual proteins or other transporters involved in APGS entry into the neural cells is of interest in order to exploit them to achieve optimal pharmacological effects by dPGS in the nervous system and other tissues.

To further investigate the impact of dPGS on the metabolic activity of N9 microglia in a normal and activated state, MTT assays were performed (Figure 4). After an acute injury in vivo, activated microglia exhibit a protective effect and promote tissue repair. ${ }^{60}$ In contrast, if chronically stimulated by an inflammogen, such as LPS, microglia become deleterious, thereby contributing to the neuronal function impairment. ${ }^{61}$ When exposing microglia to dPG or dPGS at a concentration of $100 \mathrm{nM}$ for $24 \mathrm{~h}$, no reduced mitochondrial activity and cell viability was observed (Figure 4A). The exposure of microglia to dPGS even in high micromolar concentrations (up to $1 \mathrm{mM}$ ) did not cause impairment in mitochondrial function or cell death as confirmed by cell number determination after 24 and $48 \mathrm{~h}$ (data not shown). This confirms previous findings, suggesting that $\mathrm{dPGS}$ in different cell types and even in vivo is not harmful. ${ }^{16,20,62-64}$ In addition, microglia were preincubated with dPG or dPGS $(100 \mathrm{nM})$ for $3 \mathrm{~h}$, respectively, and then exposed to LPS $(100 \mathrm{ng} / \mathrm{mL})$ for $24 \mathrm{~h}$ (Figure 4B). A reduction of about $35 \%$ of the mitochondrial 
A
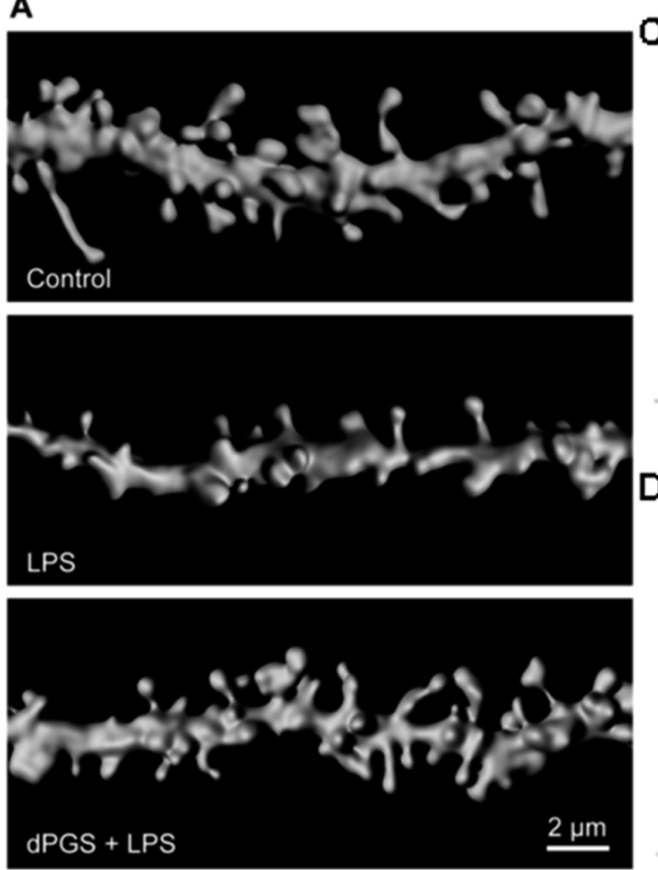

B

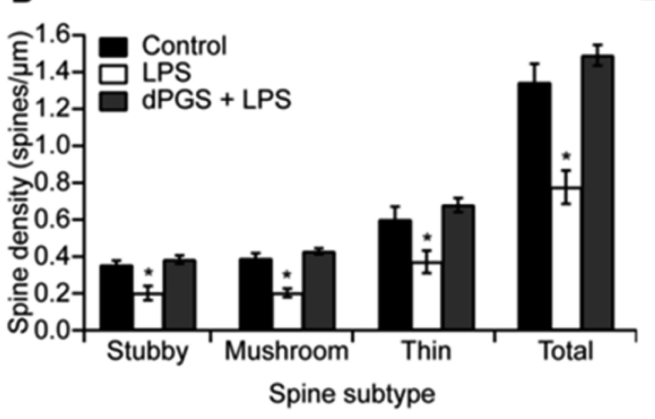

C
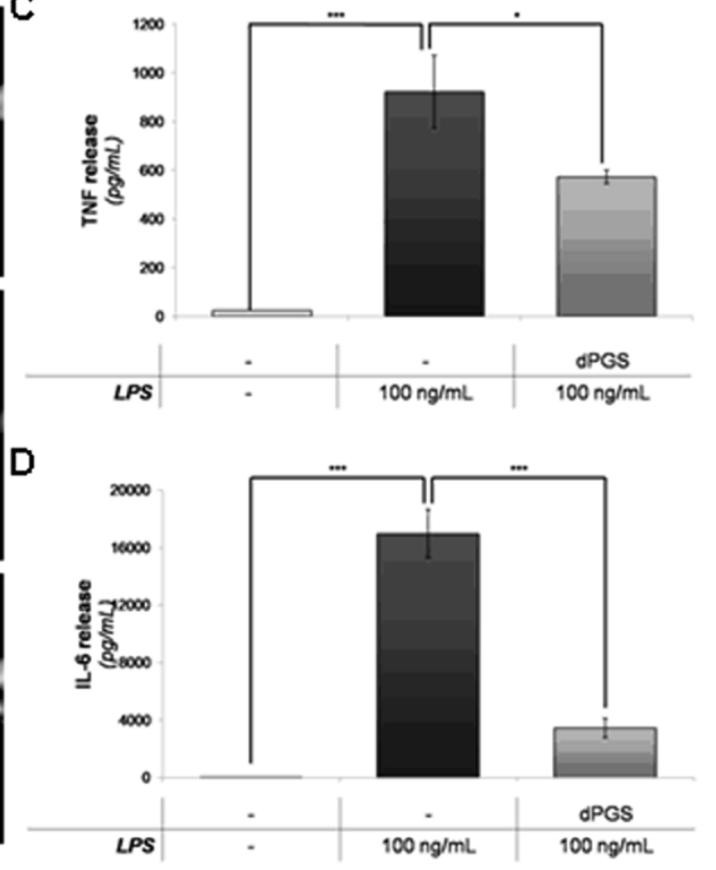

E

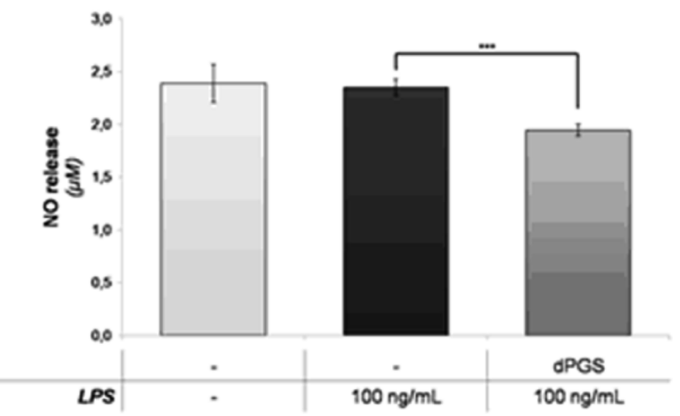

Figure 6. Postsynaptic dendritic spines morphology and biomarker production after LPS exposure. (A) Three-dimensional reconstructions of representative dendritic segments of CA1 pyramidal neurons in cultures that are treated with control, LPS (100 ng/mL), or dPGS-containing ( $100 \mathrm{nM}$ ) media. dPGS was added $3 \mathrm{~h}$ prior to the addition of LPS for $24 \mathrm{~h}$. (B) Graphical representation of dendritic spine quantification expressed as spine density per unit of dendrite length. There is a significant decrease in total spine density following LPS treatment, whereas the pretreatment with dPGS prevents dendritic spine loss caused by LPS and leads to spine densities similar to that of control cultures (values are provided in the Supporting Information, Table SI1). (C-E) Inflammatory biomarker production in mouse organotypic hippocampal slice cultures. Cultures were treated with dPGS (100 nM) for $3 \mathrm{~h}$ followed by LPS (100 ng/mL) for an additional $24 \mathrm{~h}$. (C) TNF- $\alpha$ and (D) IL-6 release were measured by ELISA. (E) NO release was measured by the Griess assay. Mean values and standard error of the means for triplicate measurements from at least two independent experiments $(n \geq 6)$ are shown. Significant differences: $*_{p}<0.05, * *_{p}<0.01, * *_{p}<0.001$.

metabolic activity was measured when treated with LPS only or when preincubated with the uncharged polymer dPG followed by LPS. In contrast, pretreatment with dPGS inhibited the reduction of mitochondrial activity to approximately $25 \%$. A quantitative determination of the cell viability via hemocytometry or measurements of labeled nuclei with Hoechst 33342 in the presence of LPS confirmed the above-described results and the lack of toxicity of dPGS (Figure 4C,D).

3. Cytokines and Nitric Oxide Release. Having seen that dPGS is avidly internalized by microglia, we investigated dPGS as regulators of nitric oxide and proinflammatory cytokines in hyperactive microglia (Figure 5). It was previously shown that the N9 microglial cell line expresses CD14 and responds to LPS by change in morphology, release of proinflammatory cytokines, and phagocytic activity. ${ }^{62,63}$ First, microglia were either exposed or unexposed to LPS $(100 \mathrm{ng} / \mathrm{mL})$ to establish the maximal NO release after $24 \mathrm{~h}$ (Figure 5A). There was a significant increase in nitrite concentrations in the media, consistent with inducible nitric oxide synthase (iNOS) activation and an enhanced NO release upon LPS exposure. When microglia were treated with dPGS (100 nM) for $3 \mathrm{~h}$ followed by incubation with LPS $(100 \mathrm{ng} / \mathrm{mL})$ for an additional $24 \mathrm{~h}$, there was a reduced NO release $(* * p<0.01)$, whereas dPG treatment did not lead to the significant change (Figure 5A). Next, the extent of protein $\mathrm{S}$-nitrosylation was determined by immunocytochemical analyses using primary antibodies recognizing nitrosilated protein species (Figure 5B). Similar to the nitrite measurements, a significant reduction of nitrosylated proteins with both lower $(10 \mathrm{nM})$ and higher (100 nM) concentrations of dPGS was observed. Consistent with these results, measurements of cytokines in the media from LPS and dPGS-treated microglia showed a small, but significant decrease of tumor necrosis factor alpha (TNF- $\alpha$, Figure 5C) and interleukin 6 (IL-6, Figure 5D); dPG was again ineffective. These results suggest that the major mode of action of 

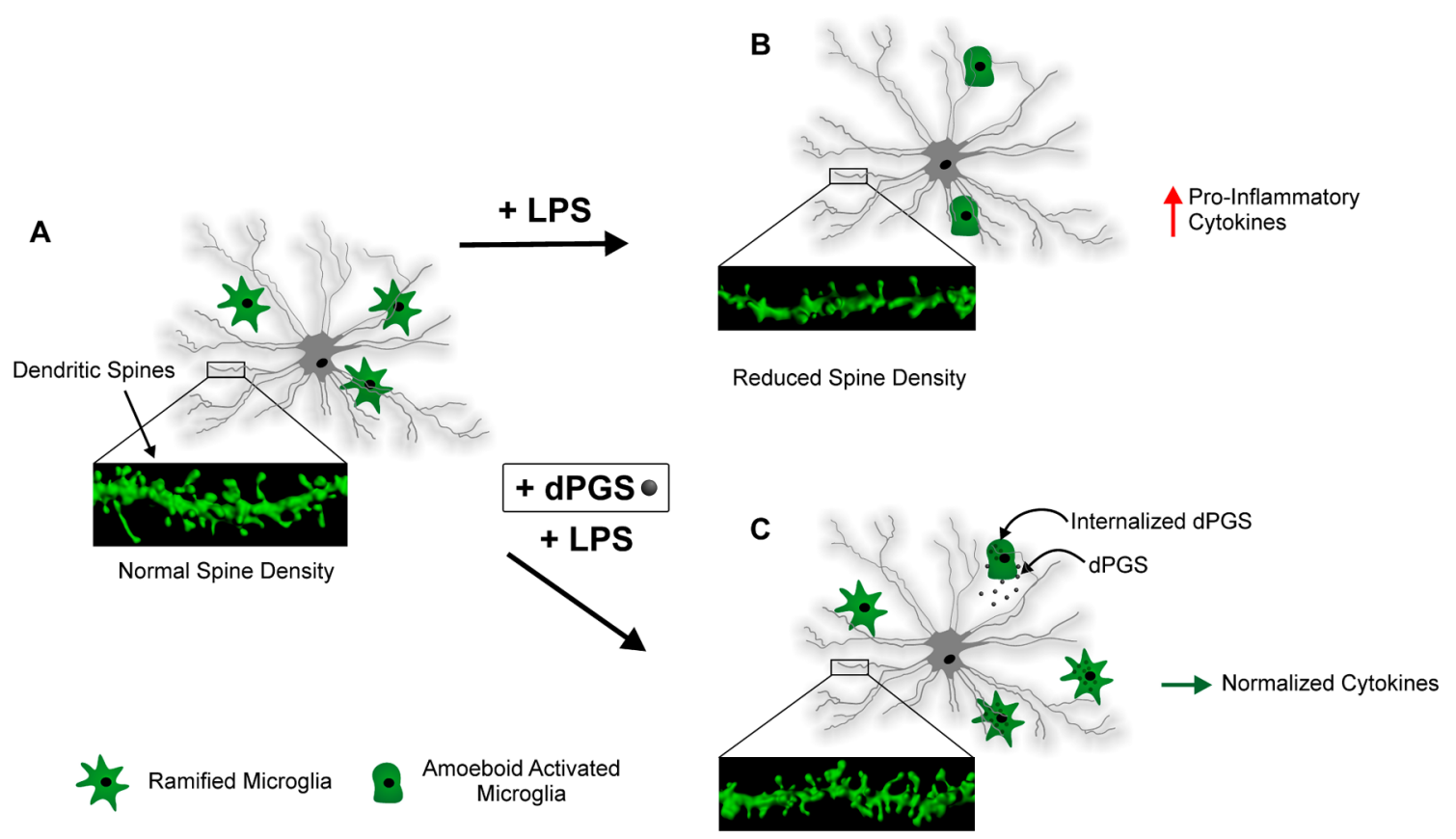

Normalized Spine Density

Figure 7. Summary of dPGS action: (A) spine morphology in organotypic cultures under normal conditions, (B) after exposure to LPS, (C) after dPGS treatment followed by LPS; (i) dPGS pretreatment (prevention) effectively reduced deleterious effects by LPS.

dPGS in hyperactive microglia stimulated by LPS was not by inhibiting a specific cytokine release, but rather by attenuating the release of several pro-inflammatory cytokines thereby reducing a cell loss. It is also possible that dPGS stimulated a secretion of some anti-inflammatory cytokines which opposed the LPS-induced proinflammatory secretion. Among the likely anti-inflammatory candidates are IL10 and TGF- $\beta$, which are currently under investigation.

4. Effect on Dendritic Spine Morphology. Considering that microglia are known modulators of dendritic spines, we also investigated the effects of dPGS and LPS on dendritic spine morphology in neuronal tissue cultures using similar treatments as in experiments with microglia alone. The effects of both LPS and DPGS alone as well as together in a sequential application were made in the CA1 region of hippocampal organotypic cultures. First, potential toxic effects of dPGS were investigated. Following dPGS treatment in various concentrations (10, 100, and $1000 \mathrm{nM}$ ) for $24 \mathrm{~h}$, there was no significant reduction in dendritic spines by dPGS at a concentration of 10 and $100 \mathrm{nM}$. However, at $1000 \mathrm{nM}$ of dPGS, there was a decrease in dendritic spine density (Supporting Information, Figure SI2 and Table SI2). Based on this finding, we have chosen the medium concentration of dPGS (100 nM) to test its ability to prevent LPS-induced inflammation in the hippocampal preparations (Figure 6). Cultures were treated with $100 \mathrm{nM}$ of dPGS for $3 \mathrm{~h}$ prior to the addition of LPS $(100 \mathrm{ng} / \mathrm{mL})$. The addition of LPS also did not lead to internalization of dPGS into CA1 neurons $(n=7$; Supporting, Figure SI1). LPS alone induced a significant decrease in dendritic spine densities in all spine subtypes compared to control condition. Three hours of dPGS pretreatment prevented spine loss associated with LPS treatment (Figure 6A,B). Having established that dPGS $(100 \mathrm{nM})$ prevents loss of spines in organotypic hippocampal cultures exposed to LPS $(100 \mathrm{ng} / \mathrm{mL})$, we next measured the ability of dPGS to reduce the biomarkers NO, TNF- $\alpha$, and IL-6, which are known to be increased in hippocampus following exposure to proinflammogen LPS. In concert with prevention of morphological spine deterioration upon LPS treatment in the presence of dPGS, there was a significant increase of NO, IL-6, and TNF- $\alpha$ release (Figure 6C-E) induced by LPS and a remarkable decrease of IL- 6 release with dPGS pretreatment $(100 \mathrm{nM})$; this decrease was $>85 \%$ (Figure $6 \mathrm{D}$ ). The reductions in TNF- $\alpha$ (Figure 6C) an NO (Figure 6E) were less dramatic ( 25 and $10 \%$, respectively) but still significant.

Taken together, the findings from the present studies suggest that dPGS is selectively taken up by microglia, which significantly improve their homeostasis during LPS-induced inflammation. This is reflected by an improved mitochondrial metabolic activity, normal cell viability, and reduced cytokine release. dPGS also prevents the loss of dendritic spines during inflammation helping to maintain and re-establish function in CA1 region, one of the particularly vulnerable structures in hippocampus. Based on our findings, we propose a simplified mechanism of dPGS for the homeostasis in hippocampus (Figure 7). dPGS is internalized by microglia and upon LPS treatment normal spine density and levels of proinflammatory cytokines are maintained, whereas treatment with LPS alone results in an inflammatory state.

\section{CONCLUSIONS}

Dendritic polyglycerol sulfate (dPGS) is a particularly attractive class of bioactive polymers that exhibits intrinsic antiinflammatory properties. The herein described studies were performed with an established model of inflammation in organotypic hippocampal cultures triggered with the commonly applied proinflammogen LPS. Results from these studies show that dPGS is internalized largely in microglia, does not impair cell viability, normalizes microglia hyperactive state, reduces production of proinflammatory cytokines, and does not adversely affect the structure of dendritic spines. Hence, dPGS thereby indirectly prevents deterioration and maintains excitatory CA1 pyramidal cell synapses when challenged with the inflammogen LPS. 
These findings suggest that dPGS could be a promising candidate for the treatment of neurological disorders associated with inflammation. The ability of dPGS as well as its conjugates and supramolecular aggregates to cross biological barriers, for example, the blood-brain barrier, is currently under investigation.

\section{ASSOCIATED CONTENT}

\section{(S Supporting Information}

Experiments describing the impact of the dPGS concentration and presence of LPS on dendritic spine density (CA1 pyramidal neurons). The Supporting Information is available free of charge on the ACS Publications website at DOI: 10.1021/acs.biomac.5b00999.

\section{AUTHOR INFORMATION}

\section{Corresponding Authors}

*Tel.: +49-(0)30-838-52633. Fax: +49-(0)30-838-53357. E-mail: haag@chemie.fu-berlin.de.

*Tel.: +1-514-398-5685. Fax: +1-514-398-2045. E-mail: anne.mckinney@mcgill.ca.

\section{Author Contributions}

${ }^{\dagger}$ These authors contributed equally (D.M. and D.G.).

\section{Notes}

The authors declare no competing financial interest.

\section{ACKNOWLEDGMENTS}

D.G. and R.H. thank the collaborative research center SFB 765 by the Deutsche Forschungsgemeinschaft (DFG) and the focus area Nanoscale of the Freie Universität Berlin (www.nanoscale. fu-berlin.de) for financial support. We acknowledge the Center for International Cooperation (CIC) of the Freie Universität Berlin for allowing intensive exchange. D.M. was supported by the Canadian Institutes for Health Research (CIHR MOP 119425) and R.A.M. was supported by Canadian Institutes for Health Research (CIHR MOP-133611) and by Natural Sciences and Engineering Research (NSERC RGPIN 341942-13). We would like to thank Francois Charron for his excellent technical assistance in making and maintaining the organotypic slice cultures, Dr. Wiebke Fischer for designing some of the enclosed figures, and Dr. Pamela Winchester for proofreading the manuscript.

\section{REFERENCES}

(1) Boridy, S.; Soliman, G. M.; Maysinger, D. Nanomedicine 2012, 7, $1149-1165$.

(2) Sousa-Herves, A.; Gröger, D.; Calderon, M.; Fernandez-Megia, E.; Haag, R. In Dendrimers in Biomedical Applications; Klajnert, B., Peng, L., Cena, V., Eds.; The Royal Society of Chemistry: Cambridge, U.K., 2013; p 56.

(3) Dai, H.; Navath, R. S.; Balakrishnan, B.; Guru, B. R.; Mishra, M. K.; Romero, R.; Kannan, R. M.; Kannan, S. Nanomedicine 2010, 5, 13171329.

(4) Wang, B.; Navath, R. S.; Romero, R.; Kannan, S.; Kannan, R. Int. J. Pharm. 2009, 377, 159-168.

(5) Iezzi, R.; Guru, B. R.; Glybina, I. V.; Mishra, M. K.; Kennedy, A.; Kannan, R. M. Biomaterials 2012, 33, 979-988.

(6) Kannan, S.; Dai, H.; Navath, R. S.; Balakrishnan, B.; Jyoti, A.; Janisse, J.; Romero, R.; Kannan, R. M. Sci. Transl. Med. 2012, 4, 130-46.

(7) Sawyer, A. J.; Kyriakides, T. R. J. Neural Eng. 2013, 10, 016013.

(8) Lesniak, W.; Mishra, M. K.; Jyoti, A.; Balakrishnan, B.; Zhang, F.; Nance, E.; Romero, R.; Kannan, S.; Kannan, R. M. Mol. Pharmaceutics 2013, 10, 4560-4571.

(9) Li, Y.; He, H.; Jia, X.; Lu, W.-L.; Lou, J.; Wei, Y. Biomaterials 2012 , 33, 3899-3908.
(10) Wagner, S.; Zensi, A.; Wien, S. L.; Tschickardt, S. E.; Maier, W.; Vogel, T.; Worek, F.; Pietrzik, C. U.; Kreuter, J.; von Briesen, H. PLoS One 2012, 7, e32568.

(11) Cerqueira, S. R.; Oliveira, J. M.; Silva, N. A.; Leite-Almeida, H.; Ribeiro-Samy, S.; Almeida, A.; Mano, J. F.; Sousa, N.; Salgado, A. J.; Reis, R. L. Small 2013, 9, 738-449.

(12) Seidlits, S. K.; Lee, J. Y.; Schmidt, C. E. Nanomedicine 2008, 3, 183-199.

(13) Tu, Q.; Li, L.; Zhang, Y.; Wang, J.; Liu, R.; Li, M.; Liu, W.; Wang, X.; Ren, L.; Wang, J. Biomaterials 2011, 32, 3253-3264.

(14) Schömer, M.; Schüll, C.; Frey, H. J. Polym. Sci., Part A: Polym. Chem. 2013, 51, 995-1019.

(15) Khandare, J.; Calderon, M.; Dagia, N. M.; Haag, R. Chem. Soc. Rev. 2012, 41, 2824-2848.

(16) Khandare, J.; Mohr, A.; Calderón, M.; Welker, P.; Licha, K.; Haag, R. Biomaterials 2010, 31, 4268-4277.

(17) Frey, H.; Haag, R. Rev. Mol. Biotechnol. 2002, 90, 257-267.

(18) Weinhart, M.; Gröger, D.; Enders, S.; Dernedde, J.; Haag, R. Biomacromolecules 2011, 12, 2502-2511.

(19) Weinhart, M.; Gröger, D.; Enders, S.; Riese, S. B.; Dernedde, J.; Kainthan, R. K.; Brooks, D. E.; Haag, R. Macromol. Biosci. 2011, 11, $1088-1098$.

(20) Dernedde, J.; Rausch, A.; Weinhart, M.; Enders, S.; Tauber, R.; Licha, K.; Schirner, M.; Zügel, U.; von Bonin, A.; Haag, R. Proc. Natl. Acad. Sci. U. S. A. 2010, 107, 19679-19684.

(21) Türk, H.; Haag, R.; Alban, S. Bioconjugate Chem. 2004, 15, 162167.

(22) Licha, K.; Welker, P.; Weinhart, M.; Wegner, N.; Kern, S.; Reichert, S.; Gemeinhardt, I.; Weissbach, C.; Ebert, B.; Haag, R.; Schirner, M. Bioconjugate Chem. 2011, 22, 2453-2460.

(23) Biffi, S.; Dal Monego, S.; Dullin, C.; Garrovo, C.; Bosnjak, B.; Licha, K.; Welker, P.; Epstein, M. M.; Alves, F. PLoS One 2013, 8, e57150.

(24) Cui, H.; Hung, A. C.; Klaver, D. W.; Suzuki, T.; Freeman, C.; Narkowicz, C.; Jacobson, G. A.; Small, D. H. PLoS One 2011, 6, e23007.

(25) Ransohoff, R. M.; Stevens, B. Science 2011, 333, 1391-1392.

(26) Kettenmann, H.; Hanisch, U.-K.; Noda, M.; Verkhratsky, A. Physiol. Rev. 2011, 91, 461-553.

(27) Aguzzi, A.; Barres, B. A.; Bennett, M. L. Science 2013, 339, 156161.

(28) Boche, D.; Perry, V. H.; Nicoll, J. A. R. Neuropathol. Appl. Neurobiol. 2013, 39, 3-18.

(29) Stevens, B.; Allen, N. J.; Vazquez, L. E.; Howell, G. R.; Christopherson, K. S.; Nouri, N.; Micheva, K. D.; Mehalow, A. K.; Huberman, A. D.; Stafford, B.; Sher, A.; Litke, A. M.; Lambris, J. D.; Smith, S. J.; John, S. W. M.; Barres, B. A. Cell 2007, 131, 1164-1178.

(30) Lenz, K. M.; Nugent, B. M.; Haliyur, R.; McCarthy, M. M. J. Neurosci. 2013, 33, 2761-2772.

(31) Tremblay, M.-È. Neuron Glia Biol. 2011, 7, 67-76.

(32) Paolicelli, R. C.; Bolasco, G.; Pagani, F.; Maggi, L.; Scianni, M.; Panzanelli, P.; Giustetto, M.; Ferreira, T. A.; Guiducci, E.; Dumas, L.; Ragozzino, D.; Gross, C. T. Science 2011, 333, 1456-1458.

(33) Tremblay, M.-E.; Majewska, A. K. Commun. Integr. Biol. 2011, 4, 220-222.

(34) Blank, T.; Prinz, M. Glia 2013, 61, 62-70.

(35) Ššková, Z.; Page, A.; O’Connor, V.; Perry, V. H. Am. J. Pathol. 2009, 175, 1610-1621.

(36) Yang, G.; Parkhurst, C. N.; Hayes, S.; Gan, W.-B. Proc. Natl. Acad. Sci. U. S. A. 2013, 110, 10306-10311.

(37) Messing, L.; Decker, J. M.; Joseph, M.; Mandelkow, E.; Mandelkow, E.-M. Neurobiol. Aging 2013, 34, 1343-1354.

(38) van Spronsen, M.; Hoogenraad, C. C. Curr. Neurol. Neurosci. Rep. 2010, 10, 207-214.

(39) McKinney, R. A. J. Physiol. 2010, 588, 107-116.

(40) Kasai, H.; Fukuda, M.; Watanabe, S.; Hayashi-Takagi, A.; Noguchi, J. Trends Neurosci. 2010, 33, 121-129.

(41) Sala, C. S. M. Physiol. Rev. 2014, 94, 141-188.

(42) Hines, D. J.; Choi, H. B.; Hines, R. M.; Phillips, A. G.; MacVicar, B. A. PLoS One 2013, 8, e60388. 
(43) Lee, E.-J.; Kim, H.-S. J. Neuroinflammation 2014, 11, 116.

(44) Kumar, A.; Chen, S.-H.; Kadiiska, M. B.; Hong, J.-S.; Zielonka, J.; Kalyanaraman, B.; Mason, R. P. Free Radical Biol. Med. 2014, 73, 51-59.

(45) Button, E.; Mitchell, A.; Domingos, M.; Chung, J. J.; Bradley, R.; Hashemi, A.; Marvyn, P.; Patterson, A.; Stark, K.; Quadrilatero, J.; Duncan, R. Lipids 2014, 49, 305-316.

(46) Duan, L.; Chen, B.-Y.; Sun, X.-L.; Luo, Z.-J.; Rao, Z.-R.; Wang, J.J.; Chen, L.-W. PLoS One 2013, 8, e73768.

(47) Stansley, B.; Post, J.; Hensley, K. J. Neuroinflammation 2012, 9, 115.

(48) Durafourt, B. A.; Moore, C. S.; Zammit, D. A.; Johnson, T. A.; Zaguia, F.; Guiot, M.-C.; Bar-Or, A.; Antel, J. P. Glia 2012, 60, 717-727.

(49) Chugh, D.; Nilsson, P.; Afjei, S.-A.; Bakochi, A.; Ekdahl, C. T. Exp. Neurol. 2013, 250, 176-188.

(50) Jakubs, K.; Bonde, S.; Iosif, R. E.; Ekdahl, C. T.; Kokaia, Z.; Kokaia, M.; Lindvall, O. J. Neurosci. 2008, 28, 12477-12488.

(51) Sunder, A.; Hanselmann, R.; Frey, H.; Mülhaupt, R. Macromolecules 1999, 32, 4240-4246.

(52) Sunder, A.; Mülhaupt, R.; Haag, R.; Frey, H. Adv. Mater. 2000, 12, 235-239.

(53) Gröger, D.; Paulus, F.; Licha, K.; Welker, P.; Weinhart, M.; Holzhausen, C.; Mundhenk, L.; Gruber, A. D.; Abram, U.; Haag, R. Bioconjugate Chem. 2013, 24, 1507-1514.

(54) Wyszogrodzka, M.; Haag, R. Langmuir 2009, 25, 5703-5712.

(55) Gähwiler, B. H.; Capogna, M.; Debanne, D.; McKinney, R. A.; Thompson, S. M. Trends Neurosci. 1997, 20, 471-477.

(56) Mayo, L.; Levy, A.; Jacob-Hirsch, J.; Amariglio, N.; Rechavi, G.; Stein, R. Glia 2011, 59, 397-412.

(57) Lim, J. P.; Gleeson, P. A. Immunol Cell Biol. 2011, 89, 836-843.

(58) Maltese, W. A.; Overmeyer, J. H. Front Physiol. 2015, 6, 1-10.

(59) Wei, T.; Chen, C.; Liu, J.; Liu, C.; Posocco, P.; Liu, X.; Cheng, Q.; Huo, S.; Liang, Z.; Fermeglia, M.; Pricl, S.; Liang, X. J.; Rocchi, P.; Peng, L. Proc Natl Acad Sci U.S.A. 2015, 112, 2978-2983.

(60) Garden, G.; Möller, T. J. Neuroimmune Pharm. 2006, 1, 127-137.

(61) Hanisch, U.-K.; Kettenmann, H. Nat. Neurosci. 2007, 10, 13871394.

(62) Stansley, B.; Post, J.; Hensley, K. J. Neuroinflammation 2012, 9, 115.

(63) Khatchadourian, A.; Bourque, S. D.; Richard, V. R.; Titorenko, V. I.; Maysinger, D. Biochim. Biophys. Acta, Mol. Cell Biol. Lipids 2012, 1821, 607-617.

(64) Gröger, D.; Kerschnitzki, M.; Weinhart, M.; Reimann, S.; Schneider, T.; Kohl, B.; Wagermaier, W.; Schulze-Tanzil, G.; Fratzl, P.; Haag, R. Adv. Healthcare Mater. 2014, 3, 375-385. 